Article

\title{
A Novel Nanowire Assembly Process for the Fabrication of CO Sensor
}

\author{
Biyao Cheng, Shuming Yang *, Tao Liu and Ali Vazinishayan
}

State Key Laboratory for Manufacturing Systems Engineering, Xi'an Jiaotong University, Xi'an 710049, China; chengbiyao@stu.xjtu.edu.cn (B.C.); liu8483@xjtu.edu.cn (T.L.); Alivazinishayan@gmail.com (A.V.)

* Correspondence: shuming.yang@mail.xjtu.edu.cn; Tel.: +86-29-8266-8616

Received: 23 March 2018; Accepted: 13 April 2018; Published: 17 April 2018

\begin{abstract}
Nanowires have been widely studied due to their outstanding mechanical and electrical properties; however, their practical applications are limited to the lack of an effective technique for controlled assembly. In the present work, zinc oxide $(\mathrm{ZnO})$ nanowire arrays were assembled via a combing process using a makeup brush and the nanodevice was fabricated. The current-voltage (I-V) and ultraviolet (UV) characteristics of the device indicate stable and repeatable electrical properties. The carbon monoxide (CO) sensing properties were tested at operating temperatures of 200, 300 and $400{ }^{\circ} \mathrm{C}$. It was found that $\mathrm{ZnO}$ based sensor exhibited the highest sensitivity to $\mathrm{CO}$ at $300{ }^{\circ} \mathrm{C}$ due to the change of dominant oxygen species. Comparing with others result, the sensitivity of the fabricated sensor exhibits higher sensing performance. The sensing mechanism of the CO sensor is also discussed.
\end{abstract}

Keywords: nanowire assembly; combing process; $\mathrm{ZnO}$; $\mathrm{CO}$ sensor

\section{Introduction}

Among different kinds of nanomaterials, nanowires have attracted great attention due to unique properties such as anisotropic structures, miniaturized dimensions, high sensitivity and fast response, which suit a variety of applications [1-12]. If nanowires could be aligned and arranged into patterns, the impact would be tremendous in many areas, from nanoscale electronics and optoelectronics to molecular sensing. Scalable and controlled assembly of nanowires, however, remains unsolved for their potential integration in nanodevice fabrication. Thus, extra efforts have been made on tackling the controlled assembly, such as using electric-field assisted alignment [13], flow assisted alignment [4], Langmuir-Blodgett (LB) technique [14-17], contact printing [18,19], super-crystalline self-assembly [20], laser-induced method [21], optical manipulation [22], etc. Smith et al. [13] developed an electric-field assisted assembly technique to position individual $\mathrm{Au}$ nanowire suspended in a dielectric medium between two electrodes on the $\mathrm{SiO}_{2}$ substrate. However, this method is limited to assembling metallic nanowires. The Langmuir-Blodgett technique is usually used to fabricate nanodevices $[23,24]$ and assemble one=dimensional nanomaterials into large-area. Kim et al. [15] applied the LB technique to assemble single layers of low aspect ratio nanorods into close-packed structures suggestive of liquid crystalline phases. Whang et al. [16] used the LB method to control organization and hierarchy of silicon nanowires in parallel. It should be noted that these techniques require complex surface modification and the alignment of nanomaterials rely on the surface pressure controlling. Fan et al. [19] developed the kind of contact printing method to transfer regular arrays of semiconductor nanowires from the donor to patterned receiver substrates; however, it might scrap the surface due to poor contact between nanowires and the substrate. Other approaches mentioned above need additional post-alignment contact, which cause significant increment in both the cost and the 
complexity. Therefore, a highly efficient and simple assembly method of nanowires is in urgent need of constructing functional nanodevice.

In this paper, a novel strategy is proposed to assemble $\mathrm{ZnO}$ nanowires by a simple combing process. Using this method, $\mathrm{ZnO}$ nanowires are well assembled on the silicon substrate and a nanodevice with nanowires assembly is fabricated. Compared with previous methods on fabricating the nanowires-based gas sensor, the approach presented here is preferable, as this simple combing method does not require expensive instruments or complex equipment.

\section{Experiment}

\subsection{Assembly Mechanism of Nanowires Using the Combing Process}

As schematically shown in Figure 1a, many nanowires are randomly dispersed and placed on the silicon substrate. A groove is fabricated by etching the photoresist. Moving a comb (a common makeup brush) from the left side to the right side can translocate the nanowires under the pressure of the comb teeth. Figure $1 \mathrm{~b}$ shows some nanowires are trapped inside the groove and forced to be orderly assembled. Meanwhile, the comb swipes away the remaining nanowires outside the groove. The makeup brush and SEM image of a single brush hair with gold coating are shown in Figure 1c. It is observed that the hair is not in regular size with diameter around 10 micrometres at the tip. However, makeup brush is a good comb candidate since the hairs of brush are flexible enough to completely touch the substrate.

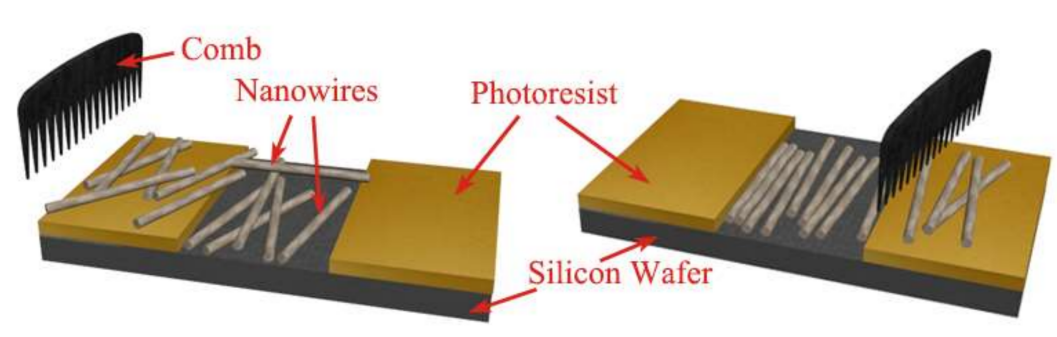

(a)

(b)

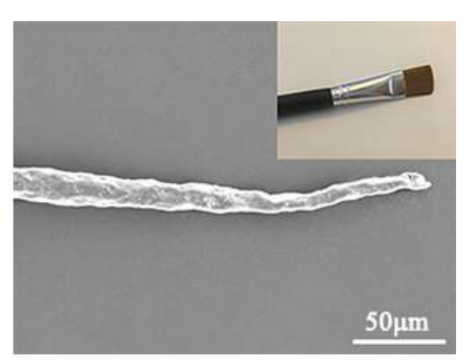

(c)

Figure 1. Schematic diagram of the combing process. Nanowires array before (a) and after combing (b). (c) A single brush hair of the makeup brush; the inset shows the makeup brush used in practice.

\subsection{Fabrication of $\mathrm{ZnO}$ Nanowire Device}

Nanostructures from $\mathrm{ZnO}$ exhibit interesting electrical characteristics due to their typical n-type conductivity [25] and they can easily absorb ultraviolet (UV) photons efficiently. Hence, a ZnO nanostructure device can be used for sensing purpose [26]. In general, one-dimensional $\mathrm{ZnO}$ nanowires can be synthesized by various kinds of techniques. In this work, $\mathrm{ZnO}$ nanowires were fabricated using a process described by Hsueh et al. [27].

To assemble nanowires on the silicon substrate and fabricate the nanodevice, the whole process is performed as depicted in Figure 2. The nanowires were steeped in deionized water, forming suspension with ultrasonic vibration for about $10 \mathrm{~min}$. (a) A drop of the suspension was dripped on the substrate, in which the nanowires were not aligned. (b) Then combing was performed at a constant velocity after air dried naturally for about $24 \mathrm{~h}$. (c) As $\mathrm{ZnO}$ nanowire became soft when external temperature reached above $400{ }^{\circ} \mathrm{C}$, the nanodevice was baked on hot plate for $\sim 10 \mathrm{~min}$ at $500{ }^{\circ} \mathrm{C}$ to make nanowires strongly adhere to the substrate via Van der Waals force. (d) The nanodevice was placed in acetone to remove the photoresist and not adhered nanowires. Likewise, the combed nanowires assemblies could be used as nanodevice to validate their performance. Finger shaped electrodes nanodevice was fabricated, as it is a popular design for electrical device [28], which can increase the contact area 
between the nanomaterials and electrodes. Hence, (e) Au electrodes were added onto top of nanowire with standard electron-beam lithography and metal deposition.

(a)

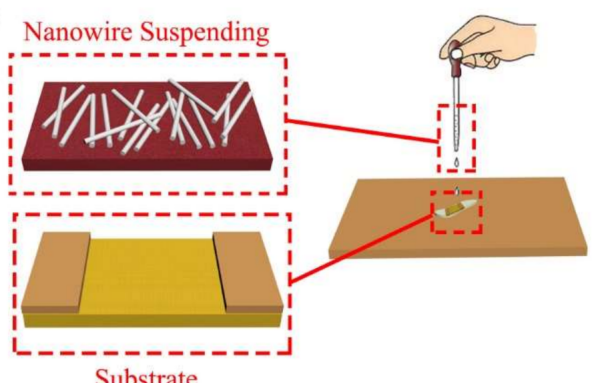

(c)

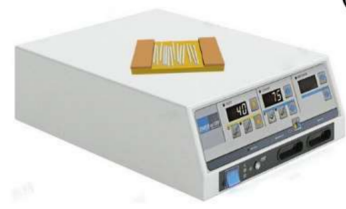

$500^{\circ} \mathrm{C}$ for $10 \mathrm{~min}$

(d) (b)
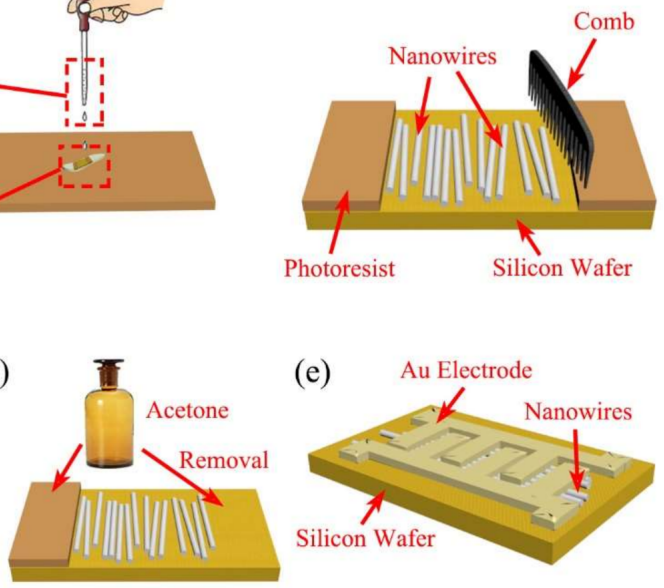

(e)

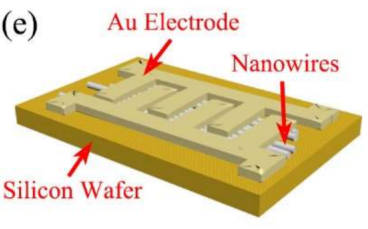

Figure 2. Simplified process flow diagram of the assembly of nanowire on the silicon substrate and nanodevice fabrication. (a) Drip a drop of the suspension on the substrate; (b) combing process after $24 \mathrm{~h}$; (c) bake on hot plate for $\sim 10 \mathrm{~min}$ at $500^{\circ} \mathrm{C}$; (d) remove the photoresist and not adhered nanowires by acetone; (e) standard electron-beam lithography and metal deposition.

\section{Results and Discussion}

\subsection{ZnO Nanowires Assembly and Nanowires Device}

Field emission scanning electron microscope (FESEM) was used to characterize the nanowire assembly results. Figure 3 a shows typical FESEM images of four $\mathrm{ZnO}$ nanowires arrays after combing on the silicon substrate. Figure $3 b$ is the zoom-in image of the first column, where all the nanowires are aligned in the same direction. To better understand the effect of combing process, the angle distribution (degree) versus percentage was measured by AutoCAD software, as shown in Figure 3c. It indicates more than $80 \%$ of the nanowires are aligned within 20 degrees with respect to the combing direction. From the image analysis, it is concluded that the combing process makes the nanowire well aligned on the substrate.

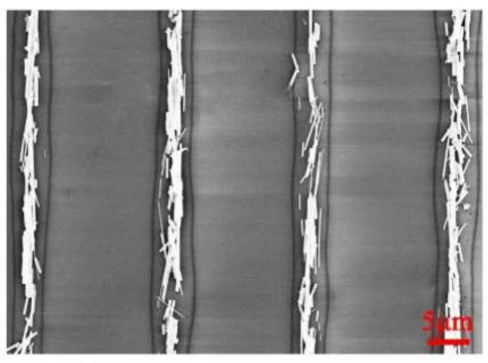

(a)

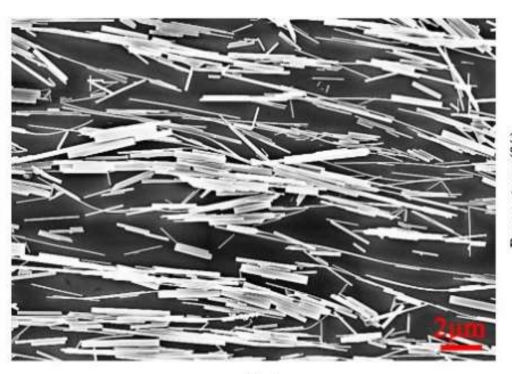

(b)

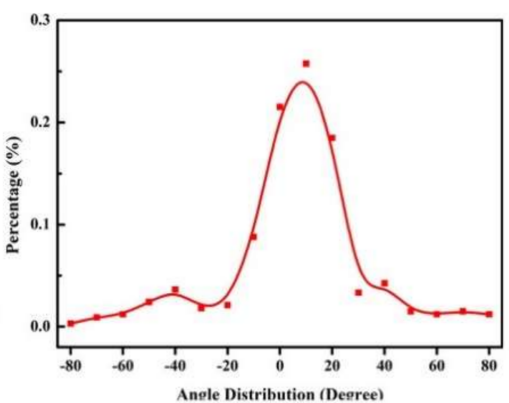

(c)

Figure 3. (a) FESEM image of four nanowires arrays; (b) the zoom-in image of the first column; and (c) the angle distribution of $\mathrm{ZnO}$ nanowire in the first column.

Figure 4a displays the FESEM image of $\mathrm{ZnO}$ sensor after adding the Au electrodes on the nanowire assembly. Totally, there are 15 electrode pairs with the width of around $3 \mathrm{~mm}$ and the length of $80 \mathrm{~mm}$ 
and the gap between two adjacent electrodes is around $2 \mathrm{~mm}$. Interestingly, Figure $4 \mathrm{~b}$ demonstrates that the $\mathrm{ZnO}$ nanowires remain aligned after the nanodevice was fabricated, which demonstrates the stability of $\mathrm{ZnO}$ nanowires fabricated with our homebrewed assembly technique.

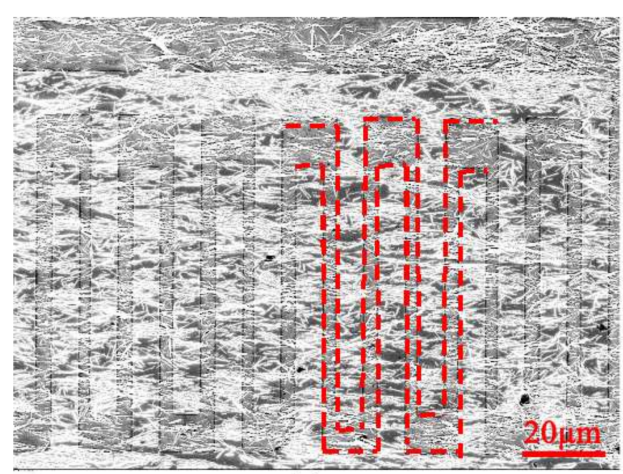

(a)

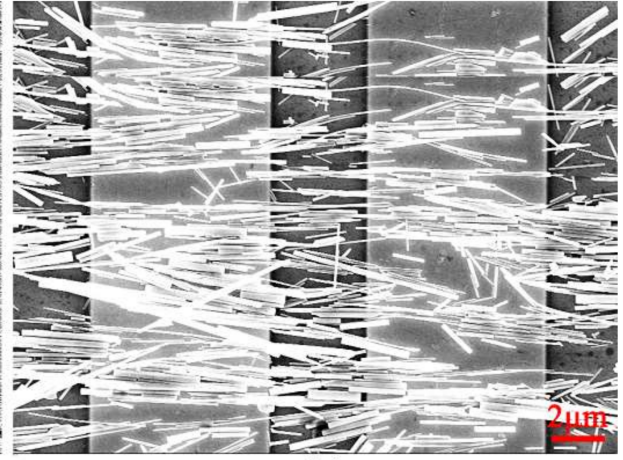

(b)

Figure 4. FESEM images of the device: (a) ZnO nanowires device with finger shape Au electrodes after the process of nanowire assembly on the Si substrate (red dotted line denotes the finger shape electrodes); and (b) the zoom-in image of the device.

\subsection{Characteristics Testing of $\mathrm{ZnO}$ Nanowire Device}

The I-V curve of the $\mathrm{ZnO}$ nanodevice is highly nonlinear and nearly symmetrical with respect to the applied voltage, as seen in Figure 5a. These I-V characteristics are typically obtained for Schottky contact and semiconductor grain boundaries $[29,30]$. These I-V curves are nearly overlapped with six repetitions which imply the current response of the sensor is remarkably stable. The current is about $76 \mu \mathrm{A}$ under the bias voltage of $1 \mathrm{~V}$, indicating a low resistance of $\sim 13 \mathrm{~K} \Omega$. Repeatability and smoothness of the I-V curve demonstrates the stable contact between nanowires and electrodes.

Generally, the carriers inside the $\mathrm{ZnO}$ nanowire are excited and jump to high energy level when irradiated by ultraviolet [31]. The UV illumination is used to test the electrical contact between nanowires and electrodes, as the UV sensing phenomenon originates from the alteration of the charge carrier density. In the experiment, the UV source was interrupted periodically to obtain the response curve of the sensor with light "ON" and the recovery curve with the light "OFF". The response behaviour of the device was characterized by measuring the current under fixed bias of $0.5 \mathrm{~V}$ as a function of time when the device was periodically exposed to the UV light, which is shown in Figure 5b. Initial current $3.3 \mu \mathrm{A}$ increased to $72.2 \mu \mathrm{A}$ under the UV illumination, which is nearly a 22-fold enhancement in response. The result is higher than the value reported by Oliver et al. [32]. Fundamentally, the photoresponse of $\mathrm{ZnO}$ is due to the photon adsorption and desorption of oxygen $[33,34]$. In the dark, oxygen molecules are absorbed on the surface of nanowire as negatively charged ions by capturing free electrons from the n-type $\mathrm{ZnO}$, leading to a depletion layer with low electrical conductivity near the nanowire surface:

$$
\mathrm{O}_{2}(\mathrm{~g})+\mathrm{e}^{-} \rightarrow \mathrm{O}_{2}^{-} \text {(ads) }
$$

UV light absorption generates electron-hole pairs and discharge the adsorbed oxygen ions through surface electron-hole recombination:

$$
\mathrm{h}^{+}+\mathrm{O}_{2}^{-}(\text {ads }) \rightarrow \mathrm{O}_{2}(\mathrm{~g})
$$

This may help to explain why the photoresponse is higher than that in Ref. [32]. The better alignment degree of the nanowires led to the larger contact area between nanowires, and therefore the ability to control the barrier height is enhanced. High performance of our device is associated with the 
multiple barriers. The UV light induced desorption of oxygen at the boundary changes the barrier height and width as well as improves UV sensitivity. As the depletion layer thickness is related to the oxygen coverage, the depletion layer width changes with absorption-desorption of oxygen.

Figure $5 c, d$ shows the fitting curves for the rising process with the light on and the decaying process with the light off, respectively. Both the ascending and descending processes can be fitted by the dual exponential curve with the form:

$$
I=I_{0}+A \exp \left(-t / \tau_{1}\right)+B \exp \left(-t / \tau_{2}\right)
$$

with estimated response time of $22.98 \mathrm{~s}$ and the decay time of $34.14 \mathrm{~s}$. In Equation (3), $I$ is the current, $I_{0}$ is the dark current, and $\tau_{1}$ and $\tau_{2}$ are the time constant of quick process and slow process, respectively. The quick process corresponds to the relaxation process which is related to the surface state of $\mathrm{ZnO}$ nanowires and that slow process corresponds to the relaxation process which is related to the deep level defect of $\mathrm{ZnO}$ nanowire.

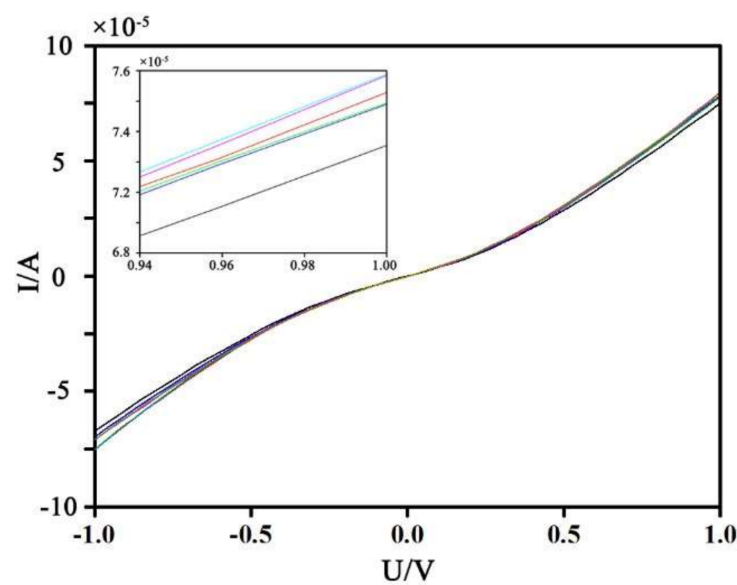

(a)

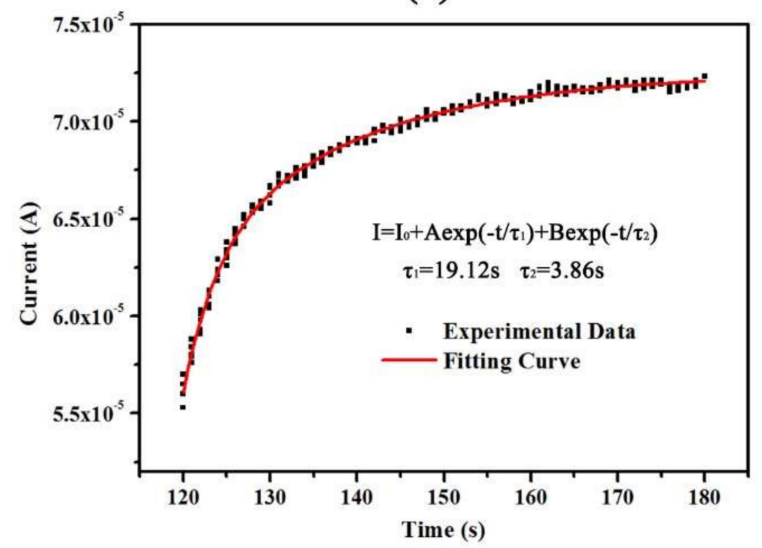

(c)

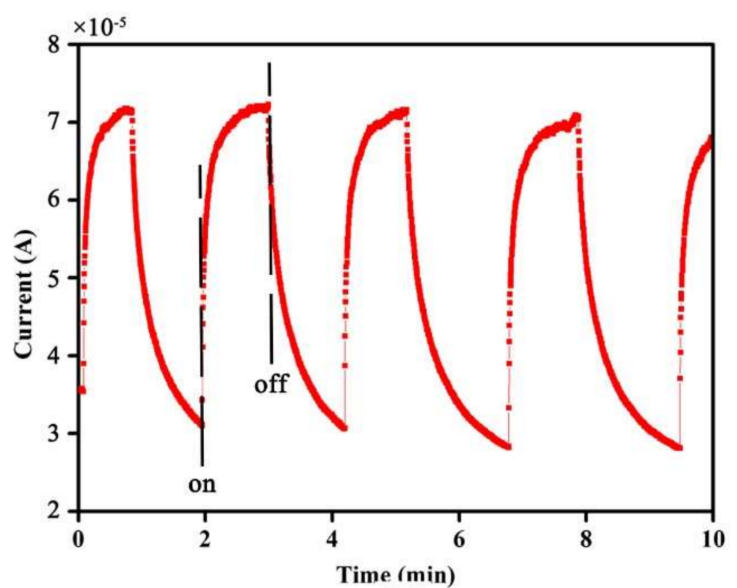

(b)

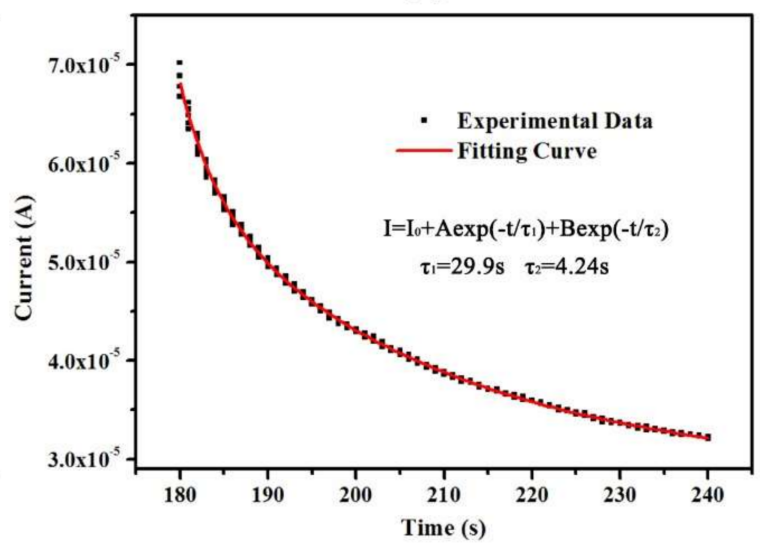

(d)

Figure 5. Characteristics testing results of $\mathrm{ZnO}$ nanowire device: (a) I-V characteristics; (b) ultraviolet characteristics at the bias voltage of $0.5 \mathrm{~V}$; (c) rising process with the light; and (d) the decaying process of the current without the light (the solid curves represent fitting curve based on Equation (3)).

\subsection{Gas sensing Properties of the $\mathrm{ZnO}$ Nanowire Assembly}

The sensitivity of the $\mathrm{ZnO}$ sensor is measured by $\mathrm{CO}$ gas. The working temperature range from $100{ }^{\circ} \mathrm{C}$ to $450{ }^{\circ} \mathrm{C}$. To avoid the failure of sensor at high temperature [35], the working temperature is set to $200{ }^{\circ} \mathrm{C}$ and the bias voltage is set to $0.3 \mathrm{~V}$. The evolution of current with time is shown in Figure 6 . 


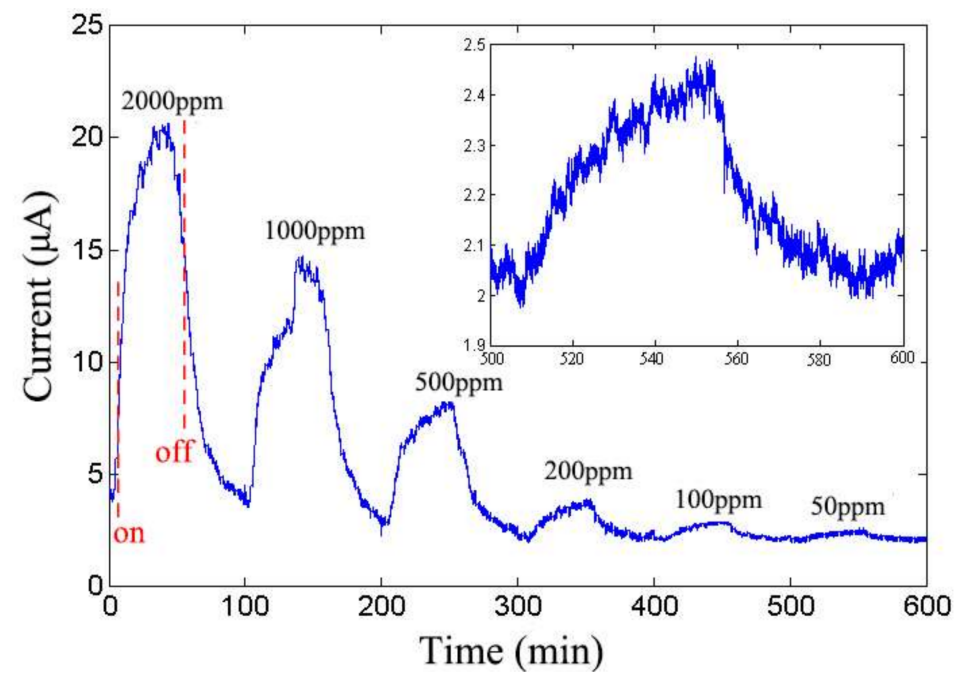

Figure 6. Evolution of nanodevice current with respect to the concentration of $\mathrm{CO}$ gas at $200{ }^{\circ} \mathrm{C}$ (inset is the zoom-in image when the CO concentration is $50 \mathrm{ppm}$ ).

"Turn on" and "Turn off" labels mean setting the target gas concentration as the determined concentration and zero, respectively. The rate of CO is $20 \mathrm{~mL} / \mathrm{min}$ and $\sim 50 \mathrm{~min}$ is needed to reach the target concentration or decreases from target concentration to zero. The $\mathrm{CO}$ sensing mechanism includes the desorption of adsorbed surface oxygen and grain boundaries in $\mathrm{ZnO}$, exchange of charges between adsorbed $\mathrm{CO}$ molecule and the $\mathrm{ZnO}$ surface leading to changes in depletion depth [36], and changes in surface or grain boundary conduction by $\mathrm{CO}$ adsorption/desorption $[37,38]$. Figure 7 shows the schematics of $\mathrm{ZnO} \mathrm{CO}$ sensor sensing mechanism.
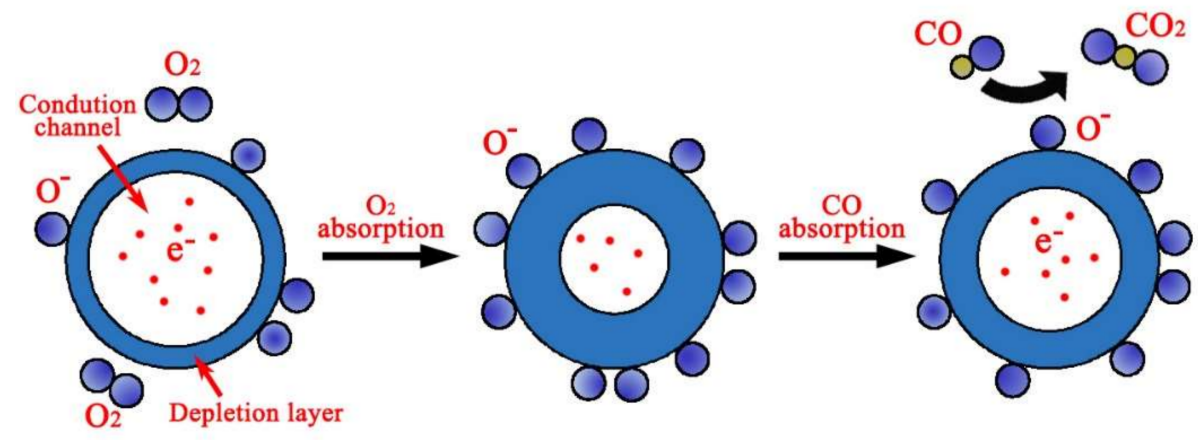

Figure 7. Schematics of $\mathrm{ZnO} \mathrm{CO}$ sensor sensing mechanism.

When $\mathrm{ZnO}$ is exposed to air atmosphere, oxygen molecules could be adsorbed on the $\mathrm{ZnO}$ surface and capture free electrons from them to form oxygen ions as described by

$$
\mathrm{O}_{2}(\mathrm{~g})+2 \mathrm{e}^{-} \rightarrow 2 \mathrm{O}^{-} \text {(ads) }
$$

The equilibrium of the chemisorption process leads to the formation of depletion layer on the surface area and the resistance of the $\mathrm{ZnO}$ sensor is increased. When $\mathrm{ZnO}$ is exposed to the $\mathrm{CO}$ gas, these molecules react with the oxygen ions and release electrons back to $\mathrm{ZnO}$, which increases the conductivity. The current of the device is increased at the same excitation voltage with respect to the increasing of $\mathrm{CO}$ concentration, which means that there exists the correlation between the current and concentration of CO. Although the sensitivity of the gas nanosensor is often defined by 
resistance [39-42] using commonly used formula, in this work, the current response of the sensor is transformed into a sensitivity value, which can be quantified by

$$
s=I_{k} /\left(I_{a i r} \times C\right)
$$

where $C$ and $I_{a i r}$ are the concentration of $\mathrm{CO}$ and the current in air, respectively. $I_{k}$ denotes the current when the concentration of $\mathrm{CO}$ is $k$. For example, $I_{500}$ denotes the current of the device when the tested $\mathrm{CO}$ is $500 \mathrm{ppm}$. It is clearly known from Equation (5) that there is a relationship between $s$ and $I_{k}$ such that $s$ is enhanced by increasing $I_{k}$. In Figure $7, I_{\text {air }}$ is less than $2 \mu \mathrm{A}$ and $I_{500}$ is $\sim 8 \mu \mathrm{A}$, hence $s_{500}$ is $8 \mu \mathrm{A} /(2 \mu \mathrm{A} \times 500 \mathrm{ppm})=0.008 \mathrm{ppm}^{-1}$.

Before comparing the results obtained, it should be mentioned that Hsueh et al. [43] measured the performance of the sensor and the sensitivity of the device was defined by $\left(R_{a}-R_{b}\right) / R_{a} \times 100 \%$, where $R_{a}$ and $R_{b}$ are resistances in air and in CO gas, respectively. The results in Ref. [43] showed that the sensitivity of the device measured at $320^{\circ} \mathrm{C}$ was around $57 \%$ when the concentration of $\mathrm{CO}$ was $500 \mathrm{ppm}$. With Equation (5), the value of sensitivity of misaligned $\mathrm{ZnO}$ CO sensor is changed to $0.00465 \mathrm{ppm}^{-1}$. To compare the sensitivity of two CO sensors, a similar temperature with the Ref. [43] is set in the ensuing discussion.

Figure 8 depicts the sensitivity of the device with respect to $\mathrm{CO}$ concentrations at different operating temperatures. It can be seen that the $\mathrm{CO}$ sensor is typically more sensitive to small concentration changes, and has high rates of response as the conduction path involves tunnelling through the depletion layer [31]. At each operating temperature, the sensitivity decreases when the $\mathrm{CO}$ gas concentration increases. The sensitivity does not exhibit significant differences when $\mathrm{CO}$ gas concentration is greater than $500 \mathrm{ppm}$ as the carrier concentration inside the nanowire approaches saturation when the concentration of the reductive gas is increased [44]. It is well accepted that the sensitivity of semiconductor gas sensors is attributed to the chemisorption of oxidizing gases in the adsorption and the oxidation of reducing gases by previously chemisorbed oxygen at the surface of the metal oxide [45]. Takata et al. [46] found that the stable oxygen ions were $\mathrm{O}^{-}$between $100{ }^{\circ} \mathrm{C}$ and $300{ }^{\circ} \mathrm{C}$, and $\mathrm{O}^{2-}$ above $300{ }^{\circ} \mathrm{C}$. The relevant reactions on the surface area are as follows

$$
\begin{aligned}
& \mathrm{CO}(\mathrm{g})+\mathrm{O}^{-}(\text {ads }) \rightarrow \mathrm{CO}_{2}(\mathrm{~g})+\mathrm{e}^{-} \\
& \mathrm{CO}(\mathrm{g})+\mathrm{O}^{2-}(\text { ads }) \rightarrow \mathrm{CO}_{2}(\mathrm{~g})+2 \mathrm{e}^{-}
\end{aligned}
$$

The molecular or atomic oxygen chemisorption captures a free electron from the conduction band giving adsorbed $\mathrm{O}^{2-}$ or $\mathrm{O}^{-}$, respectively. $\mathrm{O}_{2}$ is not reactive at all [47]. It is clear that the surface reaction in Equation (7) is more desirable for the gas sensing because the reaction could release more electrons to reduce the resistance of the nanowires and thus the gas sensitivity is increased. The surface reaction can be represented mainly by Equation (7) when the temperature is higher than $300{ }^{\circ} \mathrm{C}$. The sensing mechanism at $300{ }^{\circ} \mathrm{C}$ may involve two types of reactions, as described by Equations (6) and (7), because, at the threshold temperature of $300{ }^{\circ} \mathrm{C}$, the dominant oxygen species absorbed on the $\mathrm{ZnO}$ surface might be $\mathrm{O}^{-}$and $\mathrm{O}^{2-}$. Furthermore, increase in $\mathrm{CO}$ response with increasing the operating temperature can be explained as the thermal energy is high enough to overcome the activation energy barrier to the reaction [48]. When the operating temperature is increased to $400{ }^{\circ} \mathrm{C}$, the sensitivity of the nanodevice is decreased, possibly because these adsorbed oxygens start to desorbed from $\mathrm{ZnO}$ surface at this temperature. In addition, it is found that, when the concentration of CO is $500 \mathrm{ppm}$ at $300{ }^{\circ} \mathrm{C}$, the sensitivity of our sensor is $0.0093 \mathrm{ppm}^{-1}$, which is higher than the result from Hsueh's work at a similar temperature. This because the greater surface area of the aligned $\mathrm{ZnO}$ nanowires leads to stronger interactions between the adsorbed gases and the sensor surface, and thus the higher gas sensing sensitivity. 


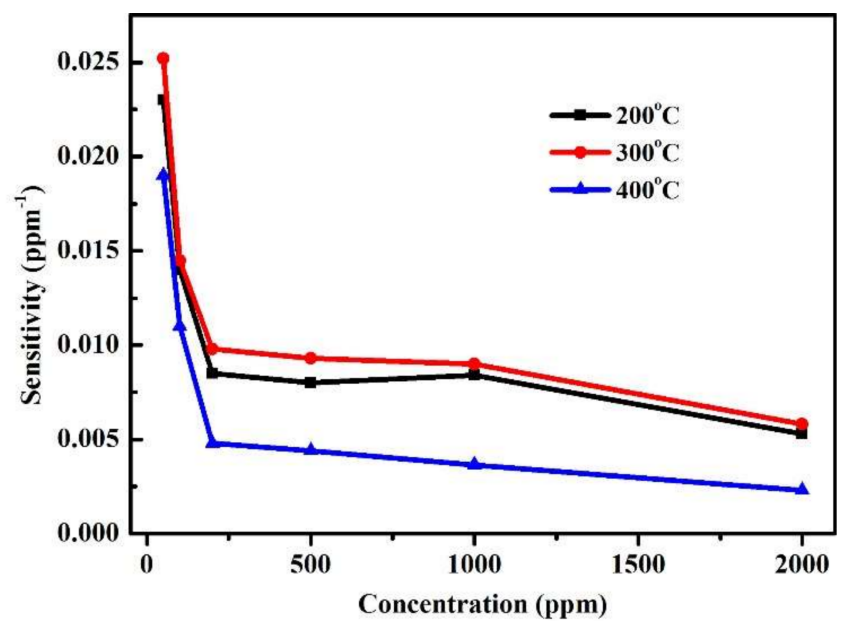

Figure 8. Relationship of sensitivity with respect to concentration of $\mathrm{CO}$ at different operating temperatures.

\section{Conclusions}

$\mathrm{ZnO}$ nanowires were orderly arranged on the silicon substrate using a common makeup brush. More than $80 \%$ of the nanowires are aligned within 20 degrees with respect to the combing direction. The I-V curve of the $\mathrm{ZnO}$ nanodevice is highly nonlinear and nearly symmetrical with respect to the applied voltage, which shows Schottky nature. The ultraviolet characteristics show nearly a 22 -fold enhancement in response due to the photon adsorption and desorption of oxygen. The carbon monoxide (CO) sensing properties were tested at operating temperatures of 200,300 and $400{ }^{\circ} \mathrm{C}$. It was found that $\mathrm{ZnO}$ based sensor exhibited the highest sensitivity to $\mathrm{CO}$ at $300{ }^{\circ} \mathrm{C}$ due to the change of dominant oxygen species. The $\mathrm{CO}$ sensor is typically more sensitive to small concentration changes and the sensitivity does not exhibit significant differences when $\mathrm{CO}$ gas concentration is greater than $500 \mathrm{ppm}$ because the carrier concentration inside the nanowire approaches saturation when the concentration of the reductive gas is increased. The $\mathrm{CO}$ sensing mechanism includes the desorption of adsorbed surface oxygen and grain boundaries in $\mathrm{ZnO}$, exchange of charges between adsorbed $\mathrm{CO}$ molecule and the $\mathrm{ZnO}$ surface leading to changes in depletion depth. Moreover, the measurement results reveal that the sensor based on assembled $\mathrm{ZnO}$ nanowire has higher sensitivity than previous sensors. In conclusion, the nanowire assembly by combing process is easy to implement and a novel fabricating technique is provided for the nanodevice.

Acknowledgments: This work is supported by the National Key R\&D Program of China (grant number 2017YFB1104700), National Science Fund for Excellent Young Scholars (No. 51722509), the National Natural Science Foundation of China (NSFC) (grant numbers 51575440 and 61505158), the 13th Five-Year Equipment Pre-research Development Project (No. 61404140203), Shaanxi Industrial Science and Technology Key Project (No. 2016GY-011) and the Young Elite Scientists Sponsorship Program by CAST (grant number 2015QNRC001).

Author Contributions: Biyao Cheng conceived and designed the experiments; Ali Vazinishayan performed the experiments; Tao Liu and Biyao Cheng analysed the data; Shuming Yang wrote the paper; Ali Vazinishayan and Tao Liu surveyed related works. All authors have read and approved the final manuscript.

Conflicts of Interest: The authors declare no conflict of interest.

\section{References}

1. Friedman, R.S.; Mcalpine, M.C.; Ricketts, D.S.; Ham, D.; Lieber, C.M. Nanotechnology: High-speed integrated nanowire circuits. Nature 2005, 434, 1085. [CrossRef] [PubMed]

2. Javey, A.; Guo, J.; Wang, Q.; Lundstrom, M.; Dai, H.J. Ballistic carbon nanotube field-effect transistors. Nature 2003, 424, 654-657. [CrossRef] [PubMed]

3. Lieber, C.M.; Wang, Z.L. Functional Nanowires. MRS Bull. 2007, 32, 99-108. [CrossRef] 
4. Huang, Y.; Duan, X.; Wei, Q.; Lieber, C.M. Directed assembly of one-dimensional nanostructures into functional networks. Science 2001, 291, 630-633. [CrossRef] [PubMed]

5. Wang, W.U.; Chen, C.; Lin, K.H.; Fang, Y.; Lieber, C.M. Label-free detection of small-molecule-protein interactions by using nanowire nanosensors. Proc. Natl. Acad. Sci. USA 2005, 102, 3208-3212. [CrossRef] [PubMed]

6. Kaps, S.; Bhowmick, S.; Gröttrup, J.; Hrkac, V.; Stauffer, D.; Guo, H.; Warren, O.L.; Adam, J.; Kienle, L.; Minor, A.M.; et al. Piezoresistive response of quasi-one-dimensional $\mathrm{ZnO}$ nanowires using an in situ electromechanical device. Acs Omega 2017, 2, 2985-2993. [CrossRef]

7. Sirbuly, D.J.; Law, M.; Haoquan, Y.A.; Yang, P. Semiconductor nanowires for subwavelength photonics integration. J. Phys. Chem. B 2005, 109, 15190-15213. [CrossRef] [PubMed]

8. Park, I.; Li, Z.; Li, X.; Pisano, A.P.; Williams, R.S. Towards the silicon nanowire-based sensor for intracellular biochemical detection. Biosens. Bioelectron. 2007, 22, 2065-2070. [CrossRef] [PubMed]

9. Wan, Q.; Li, Q.H.; Chen, Y.J.; Wang, T.H.; He, X.L.; Li, J.P.; Lin, C.L. Fabrication and ethanol sensing characteristics of $\mathrm{ZnO}$ nanowire gas sensors. Appl. Phys. Lett. 2004, 84, 3654-3656. [CrossRef]

10. Lind, E.; Persson, A.I.; Samuelson, L.; Wernersson, L.E. Improved subthreshold slope in an InAs nanowire heterostructure field-effect transistor. Nano Lett. 2006, 6, 1842-1846. [CrossRef] [PubMed]

11. Santra, S.; Guha, P.K.; Ali, S.Z.; Hiralal, P.; Unalan, H.E.; Covington, J.A.; Amaratunga, G.A.J.; Milne, W.I.; Gardner, J.W.; Udrea, F. ZnO nanowires grown on SOI CMOS substrate for ethanol sensing. Sens. Actuators B Chem. 2010, 146, 559-565. [CrossRef]

12. Ahn, M.W.; Park, K.S.; Heo, J.H.; Park, J.G.; Kim, D.W.; Choi, K.J.; Lee, J.H.; Hong, S.H. Gas sensing properties of defect-controlled ZnO-nanowire gas sensor. Appl. Phys. Lett. 2008, 93, 263103. [CrossRef]

13. Smith, P.A.; Nordquist, C.D.; Jackson, T.N.; Mayer, T.S.; Martin, B.R.; Mbindyo, J.; Mallouk, T.E. Electric-field assisted assembly and alignment of metallic nanowires. Appl. Phys. Lett. 2000, 77, 1399-1401. [CrossRef]

14. Yang, P. Nanotechnology: Wires on water. Nature 2003, 425, 243-244. [CrossRef] [PubMed]

15. Kim, F.; Kwan, S.; Akana, J.; Yang, P. Langmuir-blodgett nanorod assembly. J. Am. Chem. Soc. 2001, 123, 4360-4361. [CrossRef] [PubMed]

16. Whang, D.; Jin, S.; Wu, Y.; Lieber, C.M. Large-scale hierarchical organization of nanowire arrays for integrated nanosystems. Nano Lett. 2003, 3, 253-256. [CrossRef]

17. Mai, L.; Gu, Y.; Han, C.; Hu, B.; Chen, W.; Zhang, P.; Xu, L.; Guo, W.; Dai, Y. Orientated Langmuir-blodgett assembly of $\mathrm{VO}_{2}$ nanowires. Nano Lett. 2009, 9, 826-830. [CrossRef] [PubMed]

18. Yerushalmi, R.; Jacobson, Z.A.; Ho, J.C.; Fan, Z.; Javey, A. Large scale, highly ordered assembly of nanowire parallel arrays by differential roll printing. Appl. Phys. Lett. 2007, 91. [CrossRef]

19. Fan, Z.; Ho, J.C.; Jacobson, Z.A.; Yerushalmi, R.; Alley, R.L.; Razavi, H.; Javey, A. Wafer-scale assembly of highly ordered semiconductor nanowire arrays by contact printing. Nano Lett. 2008, 8, 20-25. [CrossRef] [PubMed]

20. Baker, J.L.; Widmer-Cooper, A.; Toney, M.F.; Geissler, P.L.; Alivisatos, A.P. Device-scale perpendicular alignment of colloidal nanorods. Nano Lett. 2010, 10, 195-201. [CrossRef] [PubMed]

21. Huang, X.; Quinto-Su, P.A.; Gonzalez-Avila, S.R.; Wu, T.; Ohl, C.D. Controlled Manipulation and in Situ Mechanical Measurement of Single Co Nanowire with a Laser-Induced Cavitation Bubble. Nano Lett. 2010, 10, 3846-3851. [CrossRef] [PubMed]

22. Pauzauskie, P.J.; Radenovic, A.; Trepagnier, E.; Shroff, H.; Yang, P.; Liphardt, J. Optical trapping and integration of semiconductor nanowire assemblies in water. Nat. Mater. 2006, 5, 97-101. [CrossRef] [PubMed]

23. Alaferdov, A.V.; Savu, R.; Rackauskas, T.A.; Rackauskas, S.; Canesqui, M.A.; de Lara, D.S.; Setti, G.O.; Joanni, E.; De Trindade, G.M.; Lima, U.B.; et al. A wearable, highly stable, strain and bending sensor based on high aspect ratio graphite nanobelts. Nanotechnology 2016, 27. [CrossRef] [PubMed]

24. Jin, S.; Whang, D.; Mcalpine, M.C.; Friedman, R.S.; Wu, Y.; Lieber, C.M. Scalable interconnection and integration of nanowire devices without registration. Nano Lett. 2004, 4, 915-919. [CrossRef]

25. Janotti, A.; Van de Walle, C.G. Fundamentals of zinc oxide as a semiconductor. Rep. Prog. Phys. $2009,72$. [CrossRef]

26. Mishra, Y.K.; Adelung, R. ZnO tetrapod materials for functional applications. Mater. Today 2017. [CrossRef] 
27. Hsueh, T.J.; Chen, Y.W.; Chang, S.J.; Wang, S.F.; Hsu, C.L.; Lin, Y.R.; Lin, T.S.; Chen, I.C. ZnO nanowire-based $\mathrm{CO}$ sensors prepared on patterned $\mathrm{ZnO}: \mathrm{Ga} / \mathrm{SiO}_{2} / \mathrm{Si}$ templates. Sens. Actuators B Chem. 2007, 125, 498-503. [CrossRef]

28. Engelen, J.B.C.; Abelmann, L.; Elwenspoek, M.C. Optimized comb drive finger shape for shock-resistant actuation. In Proceedings of the 23rd IEEE International Conference on Micro Electro Mechanical Systems, Hong Kong, China, 24-28 January 2010; Volume 20, pp. 1147-1150.

29. Blatter, G.; Greuter, F. Carrier transport through grain boundaries in semiconductors. Phys. Rev. B 1986, 33, 3952. [CrossRef]

30. Mahan, G.D.; Levinson, L.M.; Philipp, H.R. Theory of conduction in ZnO varistors. J. Appl. Phys. 1979, 50, 2799-2812. [CrossRef]

31. Rackauskas, S.; Mustonen, K.; Järvinen, T.; Mattila, M.; Klimova, O.; Jiang, H.; Tolochko, O.; Lipsanen, H.; Kauppinen, E.I.; Nasibulin, A.G. Synthesis of ZnO tetrapods for flexible and transparent UV sensors. Nanotechnology 2012, 23, 095502. [CrossRef] [PubMed]

32. Harnack, O.; Pacholski, C.; Weller, H.; Yasuda, A.; Wessels, J.M. Rectifying Behavior of Electrically Aligned ZnO Nanorods. Nano Lett. 2003, 3, 1097-1101. [CrossRef]

33. Zhang, D.H. Fast photoresponse and the related change of crystallite barriers for ZnO films deposited by RF sputtering. J. Phys. D Appl. Phys. 1995, 28, 1273. [CrossRef]

34. Choi, K.J.; Jang, H.W. One-dimensional oxide nanostructures as gas-sensing materials: Review and issues. Sensors 2010, 10, 4083-4099. [CrossRef] [PubMed]

35. Lupan, O.; Shishiyanu, S.; Chow, L.; Shishiyanu, T. Nanostructured zinc oxide gas sensors by successive ionic layer adsorption and reaction method and rapid photothermal processing. Thin Solid Films 2008, 516, 3338-3345. [CrossRef]

36. Wöllenstein, J.; Plaza, J.A.; Cané, C.; Min, Y.; Böttner, H.; Tuller, H.L. A novel single chip thin film metal oxide array. Sens. Actuators B Chem. 2003, 93, 350-355. [CrossRef]

37. Mitzner, K.D.; Sternhagen, J.; Galipeau, D.W. Development of a micromachined hazardous gas sensor array. Sens. Actuators B Chem. 2003, 93, 92-99. [CrossRef]

38. Rackauskas, S.; Barbero, N.; Barolo, C.; Viscardi, G. ZnO Nanowire Application in Chemoresistive Sensing: A Review. Nanomaterials 2017, 7, 381. [CrossRef] [PubMed]

39. Gong, H.; Hu, J.Q.; Wang, J.H.; Ong, C.H.; Zhu, F.R. Nano-crystalline Cu-doped ZnO thin film gas sensor for CO. Sens. Actuators B Chem. 2006, 115, 247-251. [CrossRef]

40. Moon, C.S.; Kim, H.R.; Auchterlonie, G. Highly sensitive and fast responding $\mathrm{CO}$ sensor using $\mathrm{SnO}_{2}$ nanosheets. Sens. Actuators B Chem. 2008, 131, 556-564. [CrossRef]

41. Shishiyanu, S.T.; Shishiyanu, T.S.; Lupan, O.I. Sensing characteristics of tin-doped $\mathrm{ZnO}$ thin films as $\mathrm{NO}_{2}$ gas sensor. Sens. Actuators B Chem. 2005, 107, 379-386. [CrossRef]

42. Tsiulyanu, D.; Marian, S.; Liess, H.D.; Eisele, I. Effect of annealing and temperature on the $\mathrm{NO}_{2}$ sensing properties of tellurium based films. Sens. Actuators B Chem. 2004, 100, 380-386. [CrossRef]

43. Hsueh, T.J.; Chen, Y.W.; Chang, S.J.; Wang, S.F.; Hsu, C.L.; Lin, Y.R.; Lin, T.S.; Chen, I.C. ZnO nanowire-based CO sensors prepared at various temperatures. J. Electrochem. Soc. 2007, 154, J393-J396. [CrossRef]

44. Fan, Z.; Lu, J.G. Gate-refreshable nanowire chemical sensors. Appl. Phys. Lett. 2005, 86, 123510. [CrossRef]

45. Moseley, P.T. Solid state gas sensors. Meas. Sci. Technol. 1997, 8, 223. [CrossRef]

46. Takata, M.; Tsubone, D.; Yanagida, H. Dependence of Electrical Conductivity of ZnO on Degree of Sintering. J. Am. Ceram. Soc. 1976, 59, 4-8. [CrossRef]

47. Morrison, S.R. Mechanism of Semiconductor Gas Sensor Operation. Sens. Actuators B Chem. 1987, 11, 283-287. [CrossRef]

48. Chang, J.F.; Kuo, H.H.; Leu, I.C.; Hon, M.H. The effects of thickness and operation temperature on ZnO: Al thin film CO gas sensor. Sens. Actuators B Chem. 2002, 84, 258-264. [CrossRef]

(C) 2018 by the authors. Licensee MDPI, Basel, Switzerland. This article is an open access article distributed under the terms and conditions of the Creative Commons Attribution (CC BY) license (http://creativecommons.org/licenses/by/4.0/). 